\title{
NeXT UP: A PROPOSAl FOR VALUES-BASED LAW REFORM ON UNILATERAL WITHHOLDING AND WITHDRAWAL OF Potentially Life-Sustaining TREATMENT
}

\author{
JOCELYN DOWNIE, ${ }^{*}$ LINDY WILLMOTT, ${ }^{* *}$ \\ AND BEN P. WHITE ${ }^{* * *}$
}

\begin{abstract}
The unilateral withholding and withdrawal of potentially life-sustaining treatment presents a complex issue of law and public policy. The authors examine the current state of this practice and conclude that it is occurring, being challenged in the courts, and is treated differently in different jurisdictions. The authors review the current state of the law in the United Kingdom, Australia, New Zealand, the United States, and Canada. The authors use Canada as a case study to outline a process for pursuing law reform. The authors propose a model for law and policy reform in this area that is both informed and shaped by the fundamental values of Canadian society.
\end{abstract}

\section{TABLE OF CONTENTS}

I. INTRODUCTION . . . . . . . . . . . . . . . . . . . . . . . 803

II. What Do We KNOW About What IS GoING ON

in Relation to THIS ISSUE? . . . . . . . . . . . . . . . . . . . . . 805

A. UNILATERAL WiTHHOLDING AND WITHDRAWAL

OF TREATMENT IS HAPPENING $\ldots \ldots \ldots \ldots \ldots \ldots \ldots \ldots \ldots$

B. It IS Controversial $\ldots \ldots \ldots \ldots \ldots \ldots \ldots \ldots \ldots \ldots \ldots$

C. It Is Being Challenged $\ldots \ldots \ldots \ldots \ldots \ldots \ldots \ldots \ldots \ldots$

D. It is Not the SAme the World Over $\ldots \ldots \ldots \ldots \ldots \ldots \ldots . \ldots . \ldots 6$

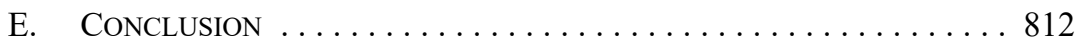

III. So What Should Be Done? A CaSe for Future LaW Reform $\ldots . .812$

A. Fundamental VAlues as EXPRESSED IN THE

CANADIAN LEGAL SYSTEM AND IMPLICATIONS FOR THE LAW

ON UnILATERAL DECISION-MAKING $\ldots \ldots \ldots \ldots \ldots \ldots \ldots 13$

IV. A Proposed MOdEL . . . . . . . . . . . . . . . . . . . . . . . . 824

A. Statute not Common Law $\ldots \ldots \ldots \ldots \ldots \ldots \ldots \ldots \ldots$

B. Decision-Making Power .................... 825

C. Provide Requested Treatment That Can

Work EXCEPT IF LAWFUL EXCUSE $\ldots \ldots \ldots \ldots \ldots \ldots \ldots$

V. CONCLUSION AND A ForWARd-LoOKIng ChaLlenge $\ldots \ldots \ldots \ldots 828$

\section{INTRODUCTION}

As the legalization of assisted dying shifts from a project for law reform to one of implementation, the gaze of Canadian end of life law and policy academics and practitioners

* SJD, University Research Professor, Faculties of Law and Medicine, Dalhousie University, Halifax, Nova Scotia. Adjunct Professor, Australian Centre for Health Law Research, Faculty of Law, Queensland University of Technology, Brisbane, Australia.

** PhD, Professor, Director, Australian Centre for Health Law Research, Faculty of Law, Queensland

University of Technology, Brisbane, Australia.

*** DPhil, Professor, Director, Australian Centre for Health Law Research, Faculty of Law, Queensland University of Technology, Brisbane, Australia. 
should be turned quickly to another pressing issue - the unilateral withholding and withdrawal of potentially life-sustaining treatment. ${ }^{1}$ What should happen when the health care team believes that treatment should not be provided and the patient's loved ones believe that it should? While the future of end of life law and policy no doubt includes many other issues, ${ }^{2}$ this is an urgent and immediate issue for Canada as well as a number of other countries (for example, the United States, Australia, and New Zealand) and a more distant (but inevitable) issue for many other countries as they move beyond the debate about whether to even allow the withholding or withdrawal of potentially life-sustaining treatment (for example, South Korea ${ }^{3}$ ).

In many countries, courts, hospitals, health care professionals, patients, and their families and friends are wrestling with gut-wrenching conflicts that can arise when the health care team believes that treatment should not be provided and the patient's loved ones believe that it should. Occasionally, details of specific cases spill over into the media, engaging the public in the often heated debate. Talk of "unrealistic expectations," "false hope," and "futility" abounds, and tests for defensible withholding or withdrawal of treatment, such as "a reasonable prospect of returning a patient to a meaningful quality of life" and "accepted medical practice" are proposed.

In this article, we attempt to take a step back from the drama and vitriol and suggest and model an approach to law and policy reform in this area. To that end, we begin with a review of what is known about what is going on in relation to unilateral withholding and withdrawal of treatment, demonstrating that: it is happening; it is controversial; it is being challenged in courts; and, it is not being approached by the law in the same way in every country (or indeed, even in the same way within a country). We then present a process for pursuing law reform, exploring Canada as a case study, to provide a model strategy for approaching law reform in other countries and to advance the project of law reform in Canada. ${ }^{4}$ To that end, we reflect on the fundamental values that should underpin a legal framework for decisionmaking on whether potentially life-sustaining treatment should be withheld or withdrawn. These values and the ways to balance these values against each other are drawn from the constitution, legislation, the common law, conventions and treaties that have been ratified by Canada, and "fundamental values of Canadian society" within which the ethical debate about the unilateral withholding and withdrawal of potentially life-sustaining treatment is situated. We then develop a proposal for how the law could be reformed such that it will more closely align with the fundamental values it is supposed to serve. In brief, we argue that

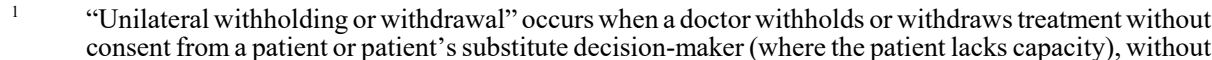
authorization from a court or tribunal, or by operation of a statute or justifiable government or institutional policy. In other words, where a doctor withholds or withdraws treatment on his or her own authority.

2 Jocelyn Downie, “Carter v Canada: What's Next for Physicians” (2015) 187:7 Can Medical Assoc J 481 .

$3 \quad$ Kim Se-Jeong, "Death With Dignity to be Allowed," The Korea Times (9 December 2015), online: $<$ www.koreatimes.co.kr/www/news/nation/2015/12/116 192836.html>.

4 Indeed, this article is adapted from another that did just this in the Australian and New Zealand context: Jocelyn Downie, Lindy Willmott \& Ben White, "Cutting the Gordian Knot of Futility: A Case for Law Reform on Unilateral Withholding and Withdrawal of Potentially Life-Sustaining Treatment" (2014) 26:1 NZULR 24.

5 Baker v Canada (Minister of Citizenship \& Immigration), [1999] 2 SCR 817 at para 56, L'HeureuxDubé [Baker]. 
the necessary law reform should be achieved through statute rather than common law. We also argue that the law reform should locate decision-making authority in the patient, the patient's substitute decision-maker, or a tribunal (not the physician). It should also establish that this decision-making authority is limited to decisions about treatment that can work and for which there is no lawful excuse for the physician not to provide (for example, a valid resource allocation policy or physical impossibility). We hope that in the end, this proposal might help us to move from friction to accord and, ultimately, to a future of better care for both the living and the dying.

\section{What Do We Know About What is Going on IN RELATION TO THIS ISSUE?}

\section{A. Unilateral WithHOLding AND WithdRAWAL OF TREATMENT IS HAPPENING}

Potentially life-sustaining treatment is being withheld and withdrawn without the knowledge of or against the wishes of patients and their substitute decision-makers. This is happening across the world. In an American study, 12 to 14 percent of physician respondents reported withdrawing or withholding life-sustaining treatment without the knowledge of a surrogate in intensive care units, and over 80 percent reported that they unilaterally withhold or withdraw life-sustaining treatment that they judge to be futile (either without the knowledge or consent of patients or their surrogates or despite clear objections). ${ }^{6}$ In a Swedish study, nearly half of the decisions to withhold or withdraw life support were made without a documented discussion with the patient or the family. When the patient is incompetent, 61 percent of physicians thought they alone should make the end-of-life decision. In contrast, 73 percent of the general public and 70 percent of nurses prefer a joint decision by the family and the physician. ${ }^{7}$ In a study of six European countries, physicians inform less than half their patients about their decisions to forgo certain treatment. ${ }^{8}$ Most recently, a Norwegian study published in 2014 found that patients were involved in the

6 David A Asch, John Hansen-Flaschen \& Paul N Lanken, "Decisions to Limit or Continue LifeSustaining Treatment by Critical Care Physicians in the United States: Conflicts Between Physicians' Practices and Patients' Wishes" (1995) 151:2 American J Respiratory \& Critical Care Medicine 288. There are, of course, many different definitions of "futility." See e.g. Susan B Rubin, When Doctors Say No: The Battleground of Medical Futility (Bloomington: Indiana University Press, 1998) at 47 [footnotes omitted]:

Treatments have variously been described as futile if they cannot achieve the goals of: postponing death; prolonging or extending life; improving, maintaining, or restoring quality of life; benefiting the patient; benefiting the patient as a whole; improving prognosis; improving the patient's comfort, well being, or general state of health; reversing or ameliorating an underlying condition; achieving immediate objectives; achieving intended physiologic effects; restoring consciousness; ending dependence on intensive medical care; preventing or curing disease; alleviating suffering; relieving symptoms; restoring function; discharging the patient to home; achieving short or long term survival; achieving the patient's goals; or achieving any of these goals.

We are not here engaging in or drawing upon the debates about definitions. Rather, we include this quote, despite its use of a problematic term, only as evidence of unilateral withholding or withdrawal of treatment.

$7 \quad$ P Sjökvist et al, "Withdrawal of Life Support - Who Should Decide?: Differences in Attitudes Among the General Public, Nurses and Physicians" (1999) 25:9 Intensive Care Medicine 949.

8 Johannes JM van Delden et al, "Do-Not-Resuscitate Decisions in Six European Countries" (2006) 34:6 Critical Care Medicine 1686. 
decision-making regarding withdrawal of treatment in only 2 percent of the cases, and patient's relatives were involved in the decision-making in 77 percent of the cases. ${ }^{9}$

\section{B. IT IS CONTROVERSIAL}

Unilateral withholding and withdrawal is also a very controversial topic. Literature searches on PubMed found over 2,000 articles on the topic, from across multiple disciplines and from around the world. Cases involving withholding and withdrawal of medical treatment also capture the attention of the public and elicit strong responses. ${ }^{10}$ Media coverage of these cases is often extensive and sometimes polarized. ${ }^{11}$

\section{IT IS BEING ChALLENGED}

Conflicts over unilateral withholding and withdrawal of potentially life-sustaining treatment are reaching courts and tribunals. Since 2003, 38 cases involving unilateral withholding and withdrawal of potentially life-sustaining treatment have been referred to the Ontario Consent and Capacity Board in Canada. ${ }^{12}$ Since 1991, there have been 27 cases before Canadian courts. By 2007, nearly 100 unilateral cases had gone before the courts in the US. ${ }^{13}$ Since 2009, 11 cases involving conflicts over unilateral withholding and withdrawal of potentially life-sustaining treatment were decided by the Court of Protection under the Mental Capacity Act $2005^{14}$ in the United Kingdom. In short, there is litigation on this issue around the world and attempts at legislating have not satisfactorily settled the conflicts.

\section{IT IS Not THE SAME THE WORLD OVER}

The legal status of unilateral withholding and withdrawal of potentially life-sustaining treatment varies considerably across jurisdictions - both in terms of the source of law that governs this issue and whether it is lawful for doctors to make these decisions unilaterally.

H Hoel et al, "Decisions to Withhold or Withdraw Life-Sustaining Treatment in a Norwegian Intensive Care Unit" (2014) 58:3 Acta Anaesthesiologica Scandinavica 329.

10 See e.g. Cutherbertson v Rasouli, 2013 SCC 53, [2013] 3 SCR 341 [Rasouli] in Canada; Aintree University Hospitals NHS Foundation Trust (Respondent) v James (Appellant), [2013] UKSC 67, [2014] AC 591 [Aintree] in the UK; Betancourt v Trinitas Hospital, 1 A (3d) 823 (NJ Super Ct (App Div) 2010) in the US.

11 Taking the Rasouli case, for example, see the contrasting coverage in Arthur Schafer, "Right-to-Die Ruling: Win for Families, Loss for Common Decency,” The Globe and Mail (18 October 2013), online: $<$ www.theglobeandmail.com/opinion/right-to-die-ruling-a-win-for-families-a-loss-for-commondecency/article14933896/>; Tom Blackwell, "Family Overjoyed as Top Court Rules Doctors Must Seek Consent Before Taking a Patient Off Life Support," National Post (18 October 2013), online: <news. nationalpost.com/news/canada/family-overjoyed-as-supreme-court-rules-doctors-must-seek-consentfrom-loved-ones-before-taking-a-patient-of-life-support>.

12 Paula Chidwick, Robert Sibbald \& Laura Hawryluck, "Best Interests at End of Life: An Updated Review of Decisions Made by the Consent and Capacity Board of Ontario" (2013) 28:1 J Critical Care 22. Thaddeus Mason Pope, "Medical Futility Statutes: No Safe Harbor to Unilaterally Refuse LifeSustaining Treatment” (2007) 75:1 Tenn L Rev 1 at 43.

Mental Capacity Act 2005, (UK) c 11 [MCA]. 


\section{THE UNITED KINGDOM}

In the United Kingdom, through both specific legislation and comprehensive and high level judicial decisions, decision-making authority rests with the physician, although more recent case law raises a presumption of consultation with patients at least in relation to decision-making about cardio-pulmonary resuscitation. In 1993, the House of Lords in Airedale N.H.S. Trust v. Bland held that doctors are not required to continue treatment or to intervene when doing so would not be in the patient's best interests. ${ }^{15}$ It is the physician who has the authority to determine whether treatment is in a patient's best interests.

Most of the case law involves interpreting the meaning of "best interests" and the proper procedure for determining the best interests of a patient who lacks capacity. The starting point for any analysis of withholding or withdrawing treatment is a strong presumption that it is in the person's best interests to stay alive. ${ }^{16}$ This presumption, however, is not absolute and there are cases where it will not be in a patient's best interests to receive life-sustaining treatment. ${ }^{17}$ In Wyatt v. Portsmouth NHS Trust, the Court elaborated on the term "best interests" and concluded that it "encompasses medical, emotional, and all other welfare issues." ${ }^{18}$ In Re A (Medical Treatment: Male Sterilisation), the Court introduced the "balance sheet" analysis whereby a patient's best interests are determined by compiling a list of benefits and drawbacks of providing treatment and weighing these relevant factors. ${ }^{19}$ The "balance sheet" analysis was used in NHS Trust v. Ms D to decide whether withholding lifesustaining medical treatment would be in the best interests of Ms. D. ${ }^{20}$ She was suffering from a terminal genetic neurological illness and was in a near vegetative state. In compiling a list of benefits and drawbacks, the Court found that there were no advantages to beginning treatment and granted a declaration stating it was not in Ms. D's best interests to begin lifesustaining measures. In recent cases, judges have asked legal counsel to provide lists of benefits and drawbacks of withholding or withdrawing treatment as part of their arguments to help complete their "balance sheet analysis." 21

The withholding or withdrawal of treatment decision-making process was clarified by the MCA, which provides legislative guidance for making a "best interests" determination. ${ }^{22}$ The MCA provides that health care providers can withhold or withdraw treatment necessary to sustain life where it is futile and is no longer in the patient's best interests to receive it. ${ }^{23} \mathrm{~A}$ process for determining a patient's best interests is set out in section 4 of the MCA along with an accompanying Code of Practice. ${ }^{24}$ The process of the physician determining what is in the

[1993] UKHL 17, [1993] AC 789 [Airedale]. Or put differently, in R (Burke) v General Medical Council, [2005] EWCA Civ 1003, [2006] QB 273 [Burke], "a patient cannot demand that a doctor administer a treatment which the doctor considers is adverse to the patient's clinical needs" (Burke, ibid at para 55).

Airedale, ibid at 801 .

Burke, supra note 15 at para 33.

[2005] EWCA Civ 1181, [2005] 1 WLR 3995 at para 87.

[2000] Lloyd's Rep Med 87 at 91-92.

[2005] EWHC 2439 (Fam), [2006] 1 FLR 638 at paras 41-42.

A Health and Social Care Trust $v M$ and $A$ and L, [2014] NIFam 3 at para 31 (HC).

MCA, supra note 14.

Ibid ("[a]n act done, or decisions made, under the Act for or on behalf of a person who lacks capacity must be done, or made, in his best interests," s 1(5)).

UK, Department for Constitutional Affairs, Mental Capacity Act 2005: Code of Practice (London: The Stationery Office, 2007). 
patient's "best interest" is that the physician must: use "professional skills" to make the determination; encourage the person to participate; consider the person's past and present wishes and feelings, beliefs and values, or any other factors the person might consider relevant; take into account views of others engaged in caring for the person or interested in his welfare; consult with the patient or his family; and try to put themselves in the place of the patient. In the face of conflict between the physician and the patient's substitute decisionmaker as to the appropriate course of action, the onus is on the substitute decision-maker to challenge the physician's decision (in the Court of Protection).

In recent cases, the Supreme Court has adopted a broad test for determining "best interests" and found that doctors must look at

\footnotetext{
welfare in the widest sense, not just medical but social and psychological; they must consider the nature of the medical treatment in question, what it involves and its prospects of success; they must consider what the outcome of that treatment for the patient is likely to be; they must try and put themselves in the place of the individual patient and ask what his attitude to the treatment is or would be likely to be; and they must consult others who are looking after him or interested in his welfare, in particular for their view of what his attitude would be. ${ }^{25}$
}

Doctors must now consider not just the medical aspects but also the social, psychological, and moral issues. They must consider the patient's wishes, views, and beliefs, and they must also consult with individuals close to the patient to help determine what these wishes might be. Perhaps as part of this trend towards more engagement with patients, a final development in the United Kingdom is the recent decision of $R$ (Tracey) $v$. Cambridge University Hospitals NHS Trust. ${ }^{26}$ In this case, the English Court of Appeal examined decision-making in relation to decisions not to provide cardio-pulmonary resuscitation. Although the Court left intact the approach to date that places this decision in the hands of physicians, it did conclude that there would generally be a duty to consult with the patient when making this decision. Patient involvement is not required, however, if doing so would be likely to cause a patient harm. The implications and scope of this case are still to be fully resolved. ${ }^{27}$

\section{AUSTRALIA}

In Australia, both the criminal and civil law regimes impose obligations on physicians relevant to providing medical care. The criminal law imposes a duty upon a person who voluntarily assumes responsibility for another who is unable to care for themselves due to mental or physical incapacity. ${ }^{28}$ In such a case, the doctor has a duty to provide the other with 
the necessaries of life ${ }^{29}$ which can include medical treatment. ${ }^{30}$ The civil law also imposes a duty on doctors to use reasonable care and skill when making treatment decisions in relation to patients. ${ }^{31}$ Where medical treatment is needed to keep a patient alive, reasonable care will often dictate the provision of treatment. Withholding or withdrawing potentially life-sustaining treatment can give rise to a breach of this civil duty if doing so falls short of exercising reasonable care and skill.

The assessment of medical treatment as futile in a given case will alter the criminal and civil law obligations just mentioned. The courts have consistently held that, where treatment is assessed as futile, a doctor is not under a duty to provide the medical treatment. There have been two bases for arriving at this conclusion.

The first is that futile treatment will be treatment that is not in the patient's best interests. ${ }^{32}$ Only a handful of Australian supreme courts have considered how to determine the best interests of a patient who lacks capacity when considering whether or not to withhold or withdraw medical treatment. In a few of these decisions, the courts have held that futile treatment is not in the best interests of the patient. ${ }^{33}$ However, there is little discussion on what makes treatment futile in the first place, and Australian supreme courts have yet to articulate a systematic approach for determining a patients' best interests. ${ }^{34}$ Importantly, case law has affirmed that doctors can determine when treatment is not in the best interests of the patient and can unilaterally withhold or withdraw treatment without the family's consent. ${ }^{35}$

The second basis is that stopping (or not providing) futile treatment will not constitute a breach of the criminal law duty to provide necessaries of life because futile treatment is not a necessary of life or because there is a lawful excuse not to provide futile treatment. ${ }^{36}$

In sum, there is no general duty on doctors to provide treatment they consider to be "futile" and doctors do not need consent from the patient or his or her substitute decisionmaker to withhold or withdraw treatment they consider to be "futile." The onus is on the substitute decision-maker to challenge the physician's decision. This is all with the exception

This duty arises in the common law jurisdictions (Australian Capital Territory, New South Wales, South Australia, and Victoria): Rv Taktak(1988), 14 NSWLR 226 (Sup Ct). It also arises in the Criminal Code jurisdictions (Northern Territory, Queensland, Tasmania, and Western Australia): Criminal Code (NT), s 149; Criminal Code Act 1899 (Qld), s 285; Criminal Code Act 1924 (Tas), s 144; and Criminal Code (WA), s 262 .

$R v$ Macdonald and Macdonald, [1904] Q St R 151 (Sup Ct); R v Nielsen \& Anor, [2001] QCA 85, 121 A Crim R 239 at para 3, Williams JA.

31 Rogers $v$ Whitaker (1992), 175 CLR 479 at 483 (HCA) (although note the civil liability legislation which has altered the common law).

32 See e.g. Messiha v South East Health, [2004] NSWSC 1061, 2004 WL 2603665 (WL Austl) [Messiha].

33 Melo $v$ Superintendent of Royal Darwin Hospital, [2007] NTSC 71, 21 NTLR 197 at para 27; Application of Herrington, Re King, [2007] VSC 151 at paras 24-25 [Re King]; Messiha, ibid at para 26.

Lindy Willmott, Ben White \& Malcolm K Smith, “'Best Interests' and Withholding and Withdrawing Life-Sustaining Treatment From an Adult who Lacks Capacity in the Parens Patriae Jurisdiction" (2014) 12:4 JL \& Medicine 920.

35 Ibid.

36 For a more detailed consideration of the relevant authorities, see Lindy Willmott, Ben White \& Jocelyn Downie, "Withholding and Withdrawal of 'Futile' Life-Sustaining Treatment: Unilateral Medical Decision-Making in Australia and New Zealand" (2013) 20:4 JL \& Medicine 907. 
of Queensland where the Guardianship and Administration Act 2000 requires consent from a substitute decision-maker before a doctor can withhold or withdraw futile treatment. ${ }^{37}$

\section{NEW ZEALAND}

In New Zealand, through a review of a fairly sparse body of case law, one can conclude that decision-making authority rests with physicians where treatment is "futile" and the approach being taken by the physician is in line with "good medical practice." ${ }^{38}$ In Shortland v. Northland Health Ltd., the New Zealand Court of Appeal held that not providing medical treatment did not breach the hospital's duty to provide the necessaries of life because it was in line with good medical practice. ${ }^{39}$ The Court held that "good medical practice" requires hospitals to engage in reasonable consultation with the patient and their family members, but does not necessarily require the fully informed consent of the patient's family. ${ }^{40}$ As in the $\mathrm{UK}$, the onus in the face of conflict with the physician is on the substitute decision-maker to challenge the physician's decision (in court). However, there remains some ambiguity in New Zealand regarding the need for the substitute decision-maker's consent where treatment is already being provided; consent may be needed where the decision is in relation to withdrawal of treatment but not if the decision is about withholding treatment. ${ }^{41}$

\section{UNITED STATES}

There is some variability across jurisdictions in the US. Some state statutes permit unilateral withholding and withdrawal of potentially life-sustaining treatment under certain circumstances. Under the Uniform Health-Care Decisions Act the physician can withhold or withdraw treatment on conscience grounds or where he or she considers the treatment "medically ineffective," standards where the physician informs the patient or substitute decision-maker of the declination to provide care, provides "continuing care to the patient until a transfer can be effected," 43 and makes "all reasonable efforts to assist in the transfer of the patient to another health-care provider or institution that is willing" 44 to provide the treatment. This legislation has been adopted in a number of states. ${ }^{45}$ Some other states have legislation that is less permissive of unilateral withholding or withdrawal than the HCDA but still do permit some unilateral withholding or withdrawal. In 1999, Texas adopted a process-based approach to resolving disputes about withholding and withdrawing treatment. The Texas Advance Directives Act establishes a process-based resolution to disputes arising from patient or surrogate demands for life-sustaining medical treatment that conflict with the doctor's

Guardianship and Administration Act 2000 (Qld). See further generally Lindy Willmott, Ben White \& Shih-Ning Then, "Withholding and Withdrawing Life-Sustaining Medical Treatment" in Ben White, Fiona McDonald \& Lindy Willmott, eds, Health Law in Australia, 2nd ed (Pyrmont, NSW: Reuters, 2014) 543 at 543-78.

For greater detail on New Zealand law, see Willmott, White \& Downie, supra note 36.

[1998] 1 NZLR 433 (CA).

Ibid at 443 .

Willmott, White \& Downie, supra note 36

Uniform Health-Care Decisions Act § 7(f) (1944) [HCDA].

Ibid, $\S 7(\mathrm{~g})(2)$.

Ibid, $§ 7(\mathrm{~g})(3)$.

Alabama, Arkansas, California, Delaware, Hawaii, Massachusetts, Mississippi, New Mexico, Tennessee, and Wyoming. 
decision. $^{46}$ The possibility of civil, criminal, or disciplinary sanctions for unilateral withholding or withdrawal remains in other states. ${ }^{47}$

\section{CANADA}

Under legislation in Ontario, physicians do not have the authority to unilaterally withdraw potentially life-sustaining treatment. The Health Care Consent Act, 1996 sets out a procedure for resolving conflicts about substitute decision-making at the end of life. ${ }^{48}$ If the patient is incapable, their designated substitute decision-maker has the right to consent on behalf of the patient, taking into consideration the patient's declared wishes and best interests. ${ }^{49}$ Physicians who disagree with the consent decision of the substitute decision-maker can challenge this decision at the Consent and Capacity Board (CCB), a specialized tribunal with the authority to make the final decision about consent for incapable patients. ${ }^{50}$ The CCB holds hearings that review capacity to consent, requests from substitute decision-makers for directions regarding wishes, and review substitute decision-makers' compliance with the rules for substitute decision-making. In the recent decision of Rasouli, the Supreme Court of Canada found that physicians are required to obtain consent from substitute decision-makers when withdrawing treatment in Ontario. ${ }^{51}$ However, the majority of the Court based its decision solely on the Ontario legislation and so did not resolve the uncertainty in the common law. ${ }^{52}$

Much remains unsettled law though with respect to physicians' authority for unilateral decision-making with respect to the withholding and withdrawal of potentially life-sustaining treatment in Canada. As noted by Chief Justice McLachlin in Rasouli: "The common law is not at all settled on this issue. While the common law has traditionally viewed consent as giving patients the right to refuse medical care rather than to refuse its withdrawal, courts have struggled with the applicability of this paradigm in the end-of-life context and have reached divergent conclusions." 53

First, even in Ontario, there has been some dispute over whether the Supreme Court's decision in Rasouli governs only withdrawal of treatment (that is, not withholding). ${ }^{54}$ However, a panel of the CCB recently concluded that Rasouli governs both withholding and withdrawal, and that health care providers must have consent to withhold or withdraw (including CPR). ${ }^{55}$ The College of Physicians and Surgeons of Ontario has issued a policy, and noted that it "is of the view that the case law is not yet clear on whether consent is

Tex Health and Safety, § 166.001 .

Pope, supra note 13.

SO 1996, c 2, Schedule A [HCCA].

Ibid, s 10(1)(b).

Ibid, ss 35-37.

Rasouli, supra note 10

Chief Justice McLachlin, writing the majority decision, emphasized that this is not a case "about who, in the absence of a statute, should have the ultimate say in whether to withhold or withdraw lifesustaining treatment.... The Court's task is simply to determine what the statute requires," ibid at para 4.

Ibid at para 53 .

James Downar et al, "Withholding and Withdrawing Treatment in Canada: Implications of the Supreme Court of Canada's Decision in the Rasouli Case" (2014) 186:16 CMAJ e622; Chris Kaposy et al, "The Distinction Between Withholding and Withdrawing Treatment in Rasouli: Providing a Solution to an Ethical Problem" (2014) 21 Health LJ 29.

55 EGJW v MGC, 2014 CanLII 49888 (Ont HPARB) (“[i]n the Board's view, the Court's remarks apply equally to the withholding of treatment and a withdrawal of treatment" at para 51). 
required prior to a physician writing a no-CPR order"56 and stated that "[a] decision regarding a no-CPR order cannot be made unilaterally by the physician." ${ }^{57}$ Plans to withhold or withdraw must be disclosed to the patient or, more commonly, the patient's substitute decision-maker. If the patient or patient's substitute decision-maker refuses to consent to the withholding or withdrawal, then the health care provider must "engage in the conflict resolution process as outlined in ... this policy which may include an application to the Consent and Capacity Board." 58

Second, outside of the context of the Ontario legislation, the law is profoundly unsettled. One set of cases holds that physicians have the final authority on the reasoning that " $t]$ he wishes of the patient's family or guardians should be taken into account, but neither their consent nor the approval of a court is required." ${ }^{, 59}$ In other cases, the courts have prevented doctors from unilaterally withdrawing or withholding treatment, but have not ruled on who has the ultimate authority to determine whether life-sustaining treatment could be withheld or withdrawn. ${ }^{60}$ Thus the law in Ontario is now relatively clear but, without legislation addressing the issue or a Supreme Court of Canada decision on the common law, the rest of the country remains in a state of confusion and controversy.

\section{E. Conclusion}

In sum, there is a range of approaches to the legal status of unilateral withholding and withdrawal in a variety of countries, and there is also variation within some of them. It ranges from clearly permitted in some jurisdictions to clearly prohibited in others, with a good deal of confusion and uncertainty in the middle. Some jurisdictions have addressed the issue directly in legislation while others have been subject to comprehensive analyses in the courts. In many countries, the issue has been addressed through brief (and inconsistent) judicial decisions or not dealt with at all.

\section{So What Should BE Done? A CASE For Future LaW REForm}

In this section of the article, we suggest a path for seeking reform in the future describing the steps in a process through the illustrative lens of the development of an argument for law reform in Canada. As noted earlier, we do this for two reasons: first, to present an argument for specific law reform for Canada; and second, to encourage others in other countries to try this process and work toward law reform in their jurisdictions.

The steps of the proposed process are as follows:

56 College of Physicians and Surgeons of Ontario, "Planning for and Providing Quality End-of-Life Care" at 8, online: <www.cpso.on.ca/CPSO/media/documents/Policies/Policy-Items/End-of-Life.pdf?ext=. pdf $>$.

Ibid at $8, \mathrm{n} 42$.

Ibid at 7 [footnote omitted].

Child and Family Services of Central Manitoba v Lavallee (1997), 154 DLR (4th) 409 at 413 (Man CA). See also Re IHV, 2008 ABQB 250, 449 AR 211; Rotaru v Vancouver General Hospital Intensive Care Unit, 2008 BCSC 318, 2008 BCSC 318 (CanLII).

$60 \quad$ See e.g. Sawatzky v Riverview Health Centre Inc, (1998), 167 DLR (4th) 359 (Man QB); Golubchuk (Committee of) v Salvation Army Grace General Hospital, 2008 MBQB 49, 290 DLR (4th) 46; Jin v Calgary Health Region, 2007 ABQB 593, [2008] 2 WWR 723. 
(1) identify the fundamental values at stake that should underpin the regulation of decisions to withhold and withdraw potentially life-sustaining treatment;

(2) articulate how these values are expressed in the existing Canadian legal system;

explore the implications of these values for the law on unilateral decision-making; and

(4) develop law reform proposals that are consistent with the values articulated.

\section{A. Fundamental VAlues as EXPRESSED In THE \\ CANADIAN LEgal SYSTEM AND IMPLICATIONS FOR THE LAW ON UNILATERAL DECISION-MAKING}

When doctors and patients (or their substitute decision-makers) disagree on whether treatment should be provided, it is critical to have laws and policies in place that can resolve the impasse. To evaluate existing and to design new laws and policies, it is necessary to take a step back and consider the values that are implicated in, and that should ground, a law and policy response to the issue at hand. The fundamental values at stake in the context of unilateral withholding and withdrawal of potentially life-sustaining treatment are, we would argue: life, autonomy, equality, the rule of law, distributive justice, procedural fairness, access to justice, conscience, and humility. We consider each in turn, both in terms of its place in the legal system and its implications for the issue at hand.

1. LIFE

Our starting point is to acknowledge the fact that the value of human life is recognized by the common law. Canadian courts have recognized the State's interest in preserving human life. ${ }^{61}$ However, life is not seen as an absolute value. The law in Canada also recognizes that the value of an individual's life can sometimes be outweighed by the disvalue of their suffering or the value of respecting their autonomy. ${ }^{62}$ In other words, a person may decide that life is no longer worth living. For this reason, the law allows a competent individual to refuse treatment, even if that treatment is necessary to preserve life and is recommended by doctors. Where a person has completed a valid advance directive, and, in some cases, where a substitute decision-maker refuses treatment, the law also allows treatment to be withheld from a person who lacks decision-making capacity. ${ }^{63}$

Rodriguez v British Columbia (Attorney General), [1993] 3 SCR 519 [Rodriguez].

Carter v Canada (Attorney General), 2015 SCC 5, [2015] 1 SCR 331; Ciarlariello v Schacter, [1993] 2 SCR 119; Nancy B v Hôtel-Dieu de Québec (1992), 86 DLR (4th) 385 (CS QC) (cases in which the courts recognized the right to refuse consent to medical treatment, or to demand that treatment be withdrawn or discontinued); $R v$ Morgentaler, [1988] 1 SCR 30; Rodriguez, ibid at 559-60 (despite the Supreme Court of Canada's conclusion on assisted suicide, the Court nonetheless confirmed that adults have the right to refuse or discontinue treatment, regardless of the results); AC v Manitoba (Director of Child and Family Services), 2009 SCC 30, [2009] 2 SCR 181 at paras 39-45 (a case in which the Court reviewed the common law for adults regarding determination of medical treatment).

63 Malette v Shulman (1990), 72 OR (2d) 417 (CA) (advance directives must be respected); Fleming $v$ Reid (1991), 4 OR (3d) 74 (CA) (the fact that serious risks or consequences, including death, may flow from the patient's decision does not negate the right of medical self-determination). 
The law recognizes the intrinsic value of life, the possibility of instrumental value for life (for the individuals and those the individual cares about), but also the fact that other values can outweigh the intrinsic and instrumental value (if any) of life for a particular individual (for example, the value of respecting autonomy, discussed below).

Therefore, the law on unilateral withholding and withdrawal of potentially life-sustaining treatment should recognize and balance the intrinsic and instrumental value of life to the person and other values of significance to that person.

\section{AUTONOMY}

The principle of respect for autonomy is also a fundamental part of Canadian common law. Most recently, it has been discussed by Chief Justice McLachlin in her majority decision in Rasouli. The majority's conception of autonomy can be drawn from the following three quotes from Chief Justice McLachlin's reasons:

- “The patient's autonomy interest — the right to decide what happens to one's body and one's life - has historically been viewed as trumping all other interests, including what physicians may think is in the patient's best interests." 64

- "The requirement for informed consent is rooted in the concepts of an individual's right to bodily integrity and respect for patient autonomy. ${ }^{\prime 65}$

- The HCCA "seeks to maintain the value of patient autonomy — the right to decide for oneself - insofar as this is possible."

As is evident from Chief Justice McLachlin's text, the Supreme Court has rejected a narrow view of autonomy understood as the right to prevent physical interference with one's bodily integrity. Rather, it has embraced the wider view of autonomy understood as selfdetermination with respect to fundamental personal choices. ${ }^{67}$

It must be noted here that the patient will not be competent in most of the cases at issue in this article. Therefore, insofar as autonomy is a relevant value, we are often dealing with past autonomy as expressed through advance directives and substitute decision-makers where the substitute decision-maker is able to represent the patient's wishes or values. For example, an individual may be an Orthodox Jew and believe that one must pursue all possible means to prolong life and so might wish treatment even in the face of a persistent vegetative state. Or an individual may believe that it would be very important for the psychological wellbeing of her children to be able to say goodbye to her while she is still alive, even if she is unconscious, and so she would want ongoing treatment until such time as her children could get to the hospital to say goodbye. An individual might believe that Chinese remedies can

Rasouli, supra note 10 at para 19.

Ibid at para 18 .

Ibid at para 78

For further discussion of concept of autonomy as understood by the Supreme Court of Canada, see Chris Kaposy \& Jocelyn Downie, "Judicial Reasoning About Pregnancy and Choice" (2008) 16:1 Health LJ 281. 
cure cancer and want aggressive Western interventions for the window of time it might take for the Chinese remedies to have a chance to be effective. In all of these cases, the doctors or the patient's family might not wish for treatment to continue but doing so would be respectful of the patient's past autonomy.

It must also be noted here that autonomy is not an absolute value. It can be outweighed by harm to others (think, for example, of the values of distributive justice, equality, and conscience).

Given the fundamental commitment to respect for autonomy, a defensible approach to the issue of withholding and withdrawal of potentially life-sustaining treatment should recognize that autonomy is violated where treatment is unilaterally withheld or withdrawn against the wishes of the patient (or substitute decision-maker), and should only permit such violation where justified by reference to some higher values.

\section{EQUALITY}

The legal landscape in Canada demonstrates its commitment to the value of equality. Section 15 of the Canadian Charter of Rights and Freedoms establishes that, "[e]very individual is equal before and under the law and has the right to the equal protection and equal benefit of the law without discrimination and, in particular, without discrimination based on race, national or ethnic origin, colour, religion, sex, age or mental or physical disability." ${ }^{\circ 8}$ Canada is also a signatory to various conventions and treaties, including the Convention on the Rights of Persons with Disabilities, which support and promote the value of equality. ${ }^{69}$ As well, Parliament and provincial legislatures have enacted human rights legislation to protect and promote equality. ${ }^{70}$

These instruments aim not only to prevent discrimination against people with disabilities, but they also strive to ensure such individuals receive the same standard of health care as the able-bodied. They also prohibit discrimination on the basis of race or culture. ${ }^{71}$ Underpinning such prohibitions is a recognition of racial and cultural diversity within Canada and the need for Canadian society to accept and respect diversity.

The value of equality is or can be critical when considering decisions to withhold or withdraw potentially life-sustaining treatment. This is particularly the case where the individual has a significant intellectual or physical impairment. There is a very real risk that the attitudes of those who are able-bodied towards disability will inappropriately colour their B to the Canada Act 1982 (UK), 1982, c 11 [Charter].

6913 December 2006, 2515 UNTS 3 (entered into force 3 May 2008) [CRPD]. The CRPD was signed by Canada on 30 March 2007 and ratified on 11 March 2010. Pursuant to this Convention, States Parties agree to prohibit all discrimination on the basis of disability (ibid, art 5).

70 Canadian Human Rights Act, RSC 1985, c H-6; Human Rights Code, RSO 1990, c H.19; Human Rights Code, RSBC 1996, c 210; Alberta Human Rights Act, RSA 2000, c A-25.5; The Human Rights Code, SM 1987-88, c 45; The Saskatchewan Human Rights Code, SS 1979, c S-24.1; Human Rights Act, RSNS 1989, c 214; Human Rights Act, RSNB 2011, c 171; Human Rights Act, 2010, SNL 2010, c H-13.1; Human Rights Act, SNWT 2002, c 18; Human Rights Act, SNu 2003, c 12; Human Rights Act, RSY 2002, c 116; Human Rights Act, RSPEI 1988, c H-12; Charter of human rights and freedoms, CQLR, c C-12. 
perception of what is in the best interests of patients in at least two ways that are contrary to the value of equality. First, they may misjudge the quality of the life of the individual in front of them (the quality as experienced by the individual). The case of Baroness Jane Campbell provides an illustration of problematic presumptions that can be made by doctors. ${ }^{72}$ Baroness Campbell has muscular atrophy and was rushed to the emergency department one evening with severe pneumonia. In her view, doctors were not prepared to treat her until they were shown photos of her receiving her doctoral award. Second, negative conclusions about the quality of life of specific individuals may send a strong message to other individuals with disabilities that their lives are worth less than those of the able-bodied. ${ }^{73}$

There is also a risk that judgments will be made that discriminate on the basis of race or culture. Health care professionals may see beliefs in non-dominant treatments as completely irrational. They may see beliefs about the value of continued life (even in a persistent vegetative state for example) as being unreasonable. This issue arose in the Australian case of Re King in which the family of Ms. King, an Aboriginal woman in a persistent vegetative state, disagreed with the health care team's decision to discontinue treatment, including the provision of antibiotics and artificial nutrition. ${ }^{74}$ The family's position was grounded in part in Aboriginal beliefs in the provision of food and drink and "caring for people who are unwell." 75 After stating that he had "considered everything said about the cultural values of aboriginal society by [the patient's family] and by the social worker," 76 Justice Williams ultimately deferred to the doctors' opinion. ${ }^{77}$

Careful attention must be paid to ensuring cultural competence ${ }^{78}$ so as to protect and promote equality with respect to race or culture. This means that decision-makers in the face of conflicts between doctors and patients' families must understand (or be able to come to understand in the context of the proceeding) the relevant cultural components of positions being taken by others. Circling back to disability, they must also understand (or be able to come to understand) the ways in which people who are differently abled than themselves perceive disability. In sum, they must also avoid basing decisions on discriminatory beliefs or attitudes and must be alert to patterns of discrimination (including indirect discrimination) in practice.

Jane Campbell, "It's My Life - It's My Decision?”(Paper delivered at the Royal Society of Medicine's Symposium on Withholding Treatment, 10 November 2004), online: Centre for Disability Studies, $<$ disability-studies.leeds.ac.uk/library/author/campbell.jane>.

73 Jocelyn Downie \& Karen McEwen, "The Manitoba College of Physicians and Surgeons Position Statement on Withholding and Withdrawal of Life Sustaining Treatment (2008): Three Problems and A Solution" (2009) 17:1 Health LJ 115.

Re King, supra note 33 .

Ibid at para 18.

Ibid at para 23.

Ibid at para 24.

Cultural competence encompasses a combination of awareness, substantive knowledge, and skills: awareness of one's own personal values, assumptions, beliefs, and biases as well as institutional and societal issues of power and oppression; substantive knowledge about a particular culture's beliefs, values, practices, and so on, as well as knowledge about the law as it impacts members of specific cultural groups; and analytical and communication skills for interacting with individuals from cultures different from one's own. See Carolyn Copps Hartley \& Carrie J Petrucci, "Practicing Culturally Competent Jurisprudence: A Collaboration Between Social Work and the Law" (2004) 14 Wash UJL \& Pol'y 133; Susan Bryant, "The Five Habits: Building Cross-Cultural Competence in Lawyers" (2001) 8:1 Clinical L Rev 33 at 50. 
It is also important to attend not just to the individual level of physician-patient interactions but also to the social level of policy-making in this arena. Given the commitment to the value of equality, any laws or policies must be subjected to rigorous equality-based analysis prior to approval; specifically, gender-, disability-, and culture-based analyses are all required. ${ }^{79}$

\section{RULE OF LAW}

A fundamental plank of the legal system in Canada is adherence to the rule of law. ${ }^{80}$ The Supreme Court of Canada has described the rule of law as "a fundamental postulate of our constitutional structure" $" 81$ and said that "the constitutional status of the rule of law is beyond question." ${ }^{82}$ Quoting Joseph Raz favourably, the Supreme Court of Canada adopted the view that "'The rule of law" means literally what it says: the rule of the law... It has two aspects: (1) that people should be ruled by the law and obey it, and (2) that the law should be such that people will be able to be guided by it." ${ }^{\prime \prime 3}$ Threats to the rule of law include: uncertainty, complexity, and lack of transparency. ${ }^{84}$

It is uncertainty in the law that poses the most serious threat to the rule of law in this area. If, after reasonable investigation and analysis of the law, it is not possible to determine what legal rights and duties arise, then the state of the law offends the rule of law. But even where the law is capable of being determined, if the state of the law makes doing so very difficult, the requirement of the rule of law that the law must be able to be ascertained can be threatened. This is particularly so in an area of law such as unilateral withholding and withdrawal where it is expected to be used by doctors, other health professionals, patients, families and carers, and the wider community without recourse to legal advice.

Another challenge to understanding the law relates to the complexity of the law in this area. The more complex the legal principle, the greater the chance that the law will not be

Gender-based analysis (GBA) is an analytical tool used to assess the differing impacts of policies and programs on different groups of women and men, boys and girls, accounting for gender and other identity factors: Status of Women Canada, "What is GBA+?" (Ottawa: SWC, 13 May 2016), online: Government of Canada <www.swc-cfc.gc.ca/gba-acs/index-en.html>; Disability and Inclusion Based Policy Analysis (DBA) assesses the sources of disadvantage that result in unequal opportunities and outcomes for people with disabilities, and assists policy-makers to develop policies and programs that overcome these disadvantages: Institute for Research and Development on Inclusion and Society, Disability and Inclusion Based Policy Analysis (Toronto: IRIS, 2012), online: $<$ https://irisinstitute.files. wordpress.com/2012/01/is-five-190142-iris_disability_inclusive_lens_eng.pdf $>$. Culture-based analysis (CBA) is used to evaluate how culture coincides with legislative, $\overline{\text { policy, }}$, and program development. The Native Women's Association of Canada calls for the implementation of a Culturally Relevant Gender Based Analysis (CRGBA), which contemplates the interconnectedness of culture and gender issues: Native Women's Association, "Culturally Relevant Gender Based Analysis: An Issue Paper," online: $<$ www.laa.gov.nl.ca/laa/naws/pdf/nwac-gba.pdf>.

80 Roncarelli v Duplessis, [1959] SCR 121 at 142 [Roncarelli]; Reference re Secession of Quebec, [1998] 2 SCR 217 at para 249 [Quebec Secession Reference]; Reference Re Manitoba Language Rights, [1985] 1 SCR 721 at 750 [Manitoba Language Reference].

$81 \quad$ Roncarelli, ibid at 142.

82 Manitoba Language Reference, supra note 80 at 750, citing Joseph Raz, The Authority of Law: Essays on Morality (Oxford, UK: Clarendon Press, 1979) at 212-13.

83 Manitoba Language Reference, ibid at 750.

84 In the Secession Reference, the Supreme Court of Canada discussed the content of the "rule of law," referring to the "subjection to known legal rules" (Quebec Secession Reference, supra note 80 at paras 70-71, citing Re Resolution to Amend the Constitution, [1981] 1 SCR 753 at 805-806. See also British Columbia (Attorney General) v Christie, 2007 SCC 21, [2007] 1 SCR 873 (the summary of the place of the "rule of law" in the Canadian legal system at paras 20-21). 
understood by those who are subject to it. We acknowledge there are likely to be intractable complexities in applying the law on withholding and withdrawing treatment. For example, there is a need to regulate various situations such as whether a patient has capacity or not. But other complexity arises from regulation in this area being spread over both common law and statute (and sometimes more than one statute). It is avoidable complexity that is of legitimate concern.

A final challenge to understanding the law in this area is that the meaning of key concepts is not transparent. Conceptual slipperiness, particularly in relation to terms that are key legal triggers, undermines the rule of law requirement that the law be ascertainable. Terms that have been the subject of considerable confusion in this area in Canada include: "futility," "medical benefit," "treatment," and "necessaries of life." 85

Given the significance of the rule of law to the Canadian legal systems, and the current challenges posed to it by the existing regulation of decisions to withhold or withdraw potentially life-sustaining treatment, the rule of law is an important value that must drive and be reflected in the project of law reform.

\section{Distributive JUSTICE}

Another consideration that can be significant in cases involving withholding and withdrawal of potentially life-sustaining treatment is the fact that resources are finite. Resources of all descriptions, including intensive care unit beds, dialysis units and organs for transplant, are in limited supply, and there will be times when giving or continuing treatment for one patient means that one or more patients do not get treatment. In addition, a dollar spent on health care may mean one less dollar spent on other forms of social services. We should not, however, hide from this fact. It is not immoral to ration resources. It happens frequently and it is necessary: no country can afford to provide all that is medically possible to everyone. But this means doctors should be transparent and not mask issues relating to scarcity of resources behind the cloak of futility.

That said, the allocation must be done in a manner consistent with the values of the legal system. ${ }^{86}$ In other words, the law accepts the need for the value of distributive justice. For our purposes in this article, the other values discussed give the content to the concept of distributive justice.

If just policies are in place, then it can be ethically defensible to deny treatment to some individuals. This includes patients who want and request the treatment and even those for whom treatment would be in their best interests. The manner in which policies on rationing should be drafted to ensure distributive justice is considered next.

85 Rubin, supra note 6 at 47; Downie \& McEwen, supra note 73; Françoise Baylis, "Expert Testimony by Persons Trained in Ethical Reasoning: The Case of Andrew Sawatzky" (2000) 28:3 JL Med \& Ethics 224 at 229.

86 See discussion of allocation of resources within the health sector in Eldridge $v$ British Columbia (Attorney General), [1997] 3 SCR 624 at paras 85, 92; Auton (Guardian ad litem of) v British Columbia (Attorney General), 2004 SCC 78, [2004] 3 SCR 657 at paras 14, 17, 36-37, 60. 


\section{PROCEDURAL FAIRNESS}

If we accept that there needs to be rationing of health care, we must engage in legitimate processes for designing resource allocation policies. ${ }^{87}$ The laws and policies must be drafted in an open and transparent fashion with input from individuals and groups with the necessary expertise (with a broad understanding of expertise, including experiential knowledge). Particularly careful attention must be paid to include the perspectives of the very individuals who are most likely to be denied treatment or have their rights or freedoms limited on the basis of the policies. Further, once these laws and policies are established, they must be challengeable in the courts or other adjudicative bodies (for example, for being discriminatory) and there must be regulation of the process.

Once specific administrative decisions are being made about the allocation of health resources, the rules of procedural fairness apply: "The fact that a decision is administrative and affects 'the rights, privileges or interests of an individual' is sufficient to trigger the application of the duty of fairness." 88 The requirements of the duty will vary with the context determined by

the notion that the purpose of the participatory rights contained within the duty of procedural fairness is to ensure that administrative decisions are made using a fair and open procedure, appropriate to the decision being made and its statutory, institutional, and social context, with an opportunity for those affected by the decision to put forward their views and evidence fully and have them considered by the decision-maker. ${ }^{89}$

Given the implications for the patient's interest in life itself, within the context of administrative decisions about withholding or withdrawing treatment, the procedural protections will have to be very stringent. The content of the duty will be driven by what is necessary in order to ensure the protection and promotion of "the right to be heard" in that context.

Of course, whether the decision-maker is a "public authority" and so owes a duty of fairness will depend on who is making the decision and under what authority. Clearly, if a physician is withholding or withdrawing treatment under an institutional policy, he or she will owe this duty (as would the institution in respect of its policy). If operating in the absence of an institutional policy, one would need to analyse the legal framework within which he or she is operating - for example, the fact that physicians in Canada are publicly-

87 One model based on "democratic deliberation" has been suggested by Leonard M Fleck, "Just Caring. Health Care Rationing, Terminal Illness, and the Medically Least Well Off” (2011) 39:2 JL Med \& Ethics 156. See also Jocelyn Downie \& Jennifer L Llewellyn, Being Relational: Reflections on Relational Theory and Health Law (Vancouver: UBC Press, 2011). For discussions of relational concepts of justice and judgment and the application of these conceptions to legitimate health policy decision-making processes, see especially Jennifer Nedelsky, “The Reciprocal Relationship of Judgment and Autonomy: Walking in Another's Shoes and Which Shoes to Walk In" in Downie \& Llewellyn (ibid) 35; Christine M Koggel, "A Relational Approach to Equality: New Developments and Applications" in Downie \& Llewellyn (ibid) 63; Diane Pothier, "Relational Theory and Resource Allocation in Health Care: Accounting for Difference" in Downie \& Llewellyn (ibid) 185; Jocelyn Downie, "Resistance is Essential: Relational Responses to Recent Law and Policy Initiative Involving Reproduction" in Downie \& Llewellyn (ibid) 209. See also Normal Daniels \& James E Sabin, Setting Limits Fairly: Learning to Share Resources for Health, 2nd ed (Oxford: Oxford University Press, 2008) (for a discussion of their "accountability reasonableness" theory of procedural justice at ch 9). Baker, supra note 5 at para 20.

Ibid at para 22. 
funded, operating under provincial health legislation (for example, consent legislation), licenced by the state, and regulated by a body given its regulatory powers by the state. A case could be made that physicians would owe a duty of fairness with respect to decision-making about end-of-life care.

Going beyond the strict application of the duty of fairness in the administrative law context, we would argue that a legal framework dealing with decision-making about medical treatment at the end of life should promote the achievement of the very outcomes protected by procedural fairness. So what then is required if procedural fairness is owed or, even if not owed, pursued as a value?

\section{As noted by the Supreme Court of Canada in Baker,}

[t] he values underlying the duty of procedural fairness relate to the principle that the individual or individuals affected should have the opportunity to present their case fully and fairly, and have decisions affecting their rights, interests, or privileges made using a fair, impartial, and open process, appropriate to the statutory, institutional, and social context of the decision. ${ }^{90}$

Broadly, procedural fairness requires that a person has adequate notice of a decision that is proposed to be made, access to relevant information and sufficient time to consider it, and an opportunity to participate in the decision-making process and be heard. ${ }^{91}$ Procedurally fair decision-making is important because it increases the quality of decision-making. When all relevant information is shared and discussed, this ensures that views, assumptions, and conclusions can be rigorously tested. ${ }^{22}$ An opportunity to participate in decision-making can also lead to greater confidence and trust in the decision that is $\operatorname{made}^{93}$ as well as a greater sense of legitimacy for the final outcome.

This would mean that decisions about not treating should not, at a minimum, occur in isolation or in secret. The value of procedurally fair decision-making requires frank engagement with the patient or his or her substitute decision-maker, and the patient (or substitute decision-maker) would be part of the properly informed decision-making process about whether treatment should be stopped.

\section{ACCESS TO JUSTICE}

The rule of law already identified as a key value in the Canadian legal system depends in part on individuals having access to justice when they feel their legal rights and freedoms (or those of a loved one) have been infringed. The connection between access to justice and the rule of law has been explicitly recognized by the Supreme Court of Canada. In Trial Lawyers Association of British Columbia v. British Columbia (Attorney General), Chief Justice McLachlin writing for the majority stated:

$91 \quad$ See ibid at paras 22, 23; Charkaoui v Canada (Citizenship and Immigration), 2007 SCC 9, [2007] 1 SCR 350 at para 53.

92 See Paul Craig, Administrative Law, 5th ed (London: Sweet \& Maxwell, 2003) at 408; HLA Hart, The Concept of Law (Oxford: Oxford University Press, 1961) at 156, 202.

93 See 2747-3174 Québec Inc v Québec (Régie des permis d'alcool), [1996] 3 SCR 919 at paras 18-23. 
This Court affirmed that access to the courts is essential to the rule of law in B.C.G.E.U. v. British Columbia (Attorney General).... As Dickson C.J. put it, "[t]here cannot be a rule of law without access, otherwise the rule of law is replaced by a rule of men and women who decide who shall and who shall not have access to justice." 94

Further, quoting Justice Karakatsanis in Hryniak v. Mauldin, "without an accessible public forum for the adjudication of disputes, the rule of law is threatened and the development of the common law undermined." 95 Threats to access to justice include: knowledge imbalances; power imbalances; high-cost dispute resolution mechanisms; and slow dispute resolution mechanisms.

In the context of the withholding and withdrawal of treatment, it must be noted that taking a matter to court is daunting and financially prohibitive for most members of the community. Delays in obtaining redress will sometimes mean that legal recourse is not a practical solution.

These systemic potential barriers to justice can arise when a patient or, more commonly, a substitute decision-maker, wishes to challenge a doctor's decision to stop potentially lifesustaining treatment. Lawyers and medical experts can be prohibitively expensive, putting the challenging of a doctor's decision beyond the reach of some if not many or, indeed, most. Power imbalances between doctors and hospitals on the one hand and lay persons on the other also reduce the willingness or ability of some to go to court to fight for what they believe to be in the best interests of their loved ones. This point was explicitly recognized by Chief Justice McLachlin in her reasons in Rasouli:

\footnotetext{
I am concerned about the practical impact of the proposed approach on patients, families, and physicians. It may heighten the vulnerability of incapable patients, since the legal burden will be on family or friends to initiate court proceedings to prevent the withdrawal of life support, rather than on physicians to obtain consent before acting. The implications of this shift are particularly troubling where the incapable patient lacks a network of family and friends with the financial resources to fund legal action, which could entail a trial on the medical standard of care. Furthermore, it is unclear on the proposed approach whether the physician could withdraw life support without judicial oversight if no legal action is taken by the patient's family or friends. 96
}

Furthermore, just as the resources of the patients and their families are limited (as noted above), and the resources of the health care system are limited (as noted in the discussion of distributive justice earlier), so too are the resources of the legal system. There are not enough lawyers who understand the complexities of end-of-life law and policy, and the court system is severely strained dealing with what is already before it. One should not establish a process that is too resource-intensive for the system to bear. It would not be practical, for example, to require that all decisions to stop treatment (whether with consent or not) be reviewed by a judge or tribunal. That said, it is also very important to be pragmatic about how many cases could not actually be resolved through effective communication strategies and conflict 
resolution mechanisms. We predict that it would be a very small number. Doctors who wish to treat a patient against the patient's family's wishes must, in most cases, go to court or tribunal for consent and this is not seen to overwhelm the system. There is no reason to suppose that the numbers would be higher for demands than for refusals. That said, the system should be designed to be as quick, effective, and efficient as it can be while serving the values outlined in this section.

Statutes can create rules, structures, and systems that reduce the need to go to court by creating efficient and accessible ways of resolving disputes. One principle of access to justice is that law should provide a framework for dispute resolution that reduces the need for judicial intervention. This is an efficiency point in that requiring judicial intervention in every case is impractical in terms of time, cost, and scarce legal system resources. It is also an access to justice issue as individuals are unlikely to be able to contest in court as effectively as well-resourced health institutions. There is also evidence that points to the value of avoiding the stress of litigation and the harm it can cause patients and their families. ${ }^{97}$ Nevertheless, intractable disputes will arise under any proposed model. When this does occur, the value of access to justice suggests that there should be efficient and accessible mechanisms, such as tribunals to assist with resolving the deadlock (as, for example, in Ontario).

\section{CONSCIENCE}

An individual's freedom of conscience is recognized in Canadian law through the Charter $^{98}$ and through its embrace of the International Covenant on Civil and Political Rights. ${ }^{99}$ The value of conscience can be implicated in cases of conflict over withholding and withdrawal. The health care professional may feel that ongoing treatment is not only not in the patient's best interests, but that to provide the treatment would run counter to the health care professional's conscience. The provision of treatment that the doctor considers to be futile, thereby depriving another patient or patients of those health resources, may also be contrary to that person's conscience. To compel the health care professional to provide treatment would be a violation of that person's freedom of conscience.

However, the request of a patient (or the patient's substitute decision-maker) for treatment may be motivated by their conscience (hence calling for the weighing of one person's conscience against another's) or may be an expression of their autonomy (hence calling for the weighing of one person's conscience against another's autonomy). We would argue that, insofar as it is possible to meet the request for treatment without violating the health care professional's conscience (for example, by transferring the patient to another health care professional), this should be permitted, and indeed facilitated, in the system. Beyond that, in the face of a refusal of consent to the withholding or withdrawal of potentially life sustaining treatment by the patient or the patient's substitute decision-maker, unless

$97 \quad$ Nicole M Zapzalka, The Psychological Impact of Civil Litigation: A Comparison of Perceived Anxiety Levels in Civil Litigation as Viewed by Trial and Alternative Dispute Resolution Litigants ( $\mathrm{PhD}$ Dissertation, Capella University, 2007) 74-75; Larry H Strasburger, "The Litigant-Patient: Mental Health Consequences of Civil Litigation” (1999) 27:2 J American Academy Psychiatry \& L 203.

98 Charter, supra note 68, s 2(a) (freedom of conscience and religion).

9919 December 1966, 999 UNTS 171 (entered into force 23 March 1976, accession by Canada 19 May 1976). 
authorized to withhold or withdraw by a court or tribunal, the doctor should be compelled, even over a conscience claim, to provide treatment. It should also be remembered that, in this kind of case, the patient is already in a therapeutic relationship with the doctor and, unless a referral to another health care professional is possible, it would be contrary to professional ethics for the doctor to cease treating the patient or to treat the patient in a way that is contrary to stated wishes.

This approach to a doctor's conscience (that is, overriding it in some circumstances when the value of respecting it is overridden by the harms of doing so) is consistent with the law's approach to compelling the cessation of treatment (even where that requires action by the doctor as in the case of removing ventilatory support or transferring the patient to a doctor who is prepared to do so). ${ }^{100}$

Chief Justice McLachlin addressed this issue in Rasouli reflecting on the role of a physician's personal ethics. ${ }^{101}$ She notes that efforts can be made to avoid clashes with "a physician's ethical compunctions," 102 for example, transferring the patient to another willing physician or institution. However, where that is not possible, she seems determined that the physician cannot withhold or withdraw treatment on the grounds of a conflict with his "personal ethics."

In sum, the law is often called upon to balance (and it does) the freedom of conscience of one person as against that of another (for example, a doctor as against a patient). In addition, as with the values of life, autonomy, and equality, the value of conscience is not absolute and can be outweighed by other values.

\section{HumiLity}

Humility arises in the context of considering who has privileged access to what information and who can best judge the various elements in the decision to withhold or withdraw treatment. Advocates of unilateral withholding and withdrawal cast doctors as having the requisite knowledge for determinations of "appropriate treatment" and "best interests." Opponents argue that patients themselves or patients' families are better situated to judge what is in the patient's best interests or, where there is reason to doubt the judgment of the patient's families, that judges and tribunals are best situated to make the substituted judgment.

There is a need for doctors to be humble. Doctors must realize that when the decision is at least partly an ethical one (namely, whether the treatment is in the patient's best interests, or is "worth doing"), they do not have privileged access to the truth. They have relevant information and their opinions, which while potentially illuminating, should not be determinative. $^{103}$ 
This should drive doctors to support a model which recognizes that others have greater expertise than they do in relation to what specific patients want or what is in their patients' best interests and, reflecting that, establishes others as the appropriate decision-makers. Such decision-makers may be a patient's legally authorized substitute decision-maker, a court, a tribunal, or policy-makers. Such a model would require doctors to obtain consent from the patient or the patient's legally authorized substitute decision-maker, or authorization from a court or tribunal where the treatment decision rests on whether the treatment is in the patient's best interests (whether seen through a straight best interests approach or through a futility lens).

Tribunals, comprised of individuals with a range of expertise (including with respect to clinical matters as well as disability, culture, and ethics) are arguably better situated than doctors to review the complex medical, moral, and social aspects of the decisions at issue in this article. Society needs to have a trusted agent to weigh all of the evidence and make the best judgment they can as between the competing positions and it has given that job to judges and tribunal members in similar contexts ${ }^{104}$ and should, for the same reasons, give it to judges or tribunals in this context.

However, they too must be humble. The need for humility on the part of courts and tribunals has actually been recognized by a court. In a 2007 Canadian case, ${ }^{105}$ doctors and parents of an eight-month-old baby in a vegetative state disagreed about treatment. The doctors wanted assisted ventilation withdrawn and the parents did not. The matter came before a Consent and Capacity Board to resolve the impasse. The mother asked two questions of the Panel: what authority the Panel had to make the decision, and why the Panel thought it was better placed than she was to do so. The Panel responded:

The answer to the first question was simple: s. 37 of the [HCCA] authorized Dr. Choong's application to the Board and required us to adjudicate. That was our authority. The answer to the second question was rather more difficult, in part because, given the nature of the treatment decision to be made, the question and the decision humbled us. ${ }^{106}$

Substitute decision-makers too should recognize that they may make mistakes regarding the patient's best interests due to, for example, the inability to fully understand and appreciate some complex science behind a treatment decision. This spirit of humility should infuse the law in this area.

\section{A Proposed MOdel}

A concrete proposal for what the law should be can be derived from the preceding discussion of the fundamental values and the implications for the issue of unilateral withholding and withdrawal. However, before proposing the model, a brief comment on the background legal context within which this proposal will sit is required. refusals of psychiatric treatment. 
The sources of relevant obligations for physicians are both the criminal and civil law regimes as well as the regulation of the medical profession. The criminal law imposes a duty upon a person (in this context, a doctor) who has someone under their charge who is unable to remove themselves from that charge and unable to provide him or herself with the necessaries of life. ${ }^{107}$ In such a case, the doctor has a duty to provide the other with the necessaries of life. ${ }^{108}$ Necessaries of life can include medical treatment, ${ }^{109}$ so criminal sanction could potentially attach to not providing treatment. The civil law also imposes a duty on doctors to use reasonable care and skill when making treatment decisions in relation to patients. ${ }^{110}$ This arises from the general law of negligence. Where medical treatment is needed to keep a patient alive, reasonable care will often dictate the provision of treatment. Withholding or withdrawing potentially life-sustaining treatment can give rise to a breach of this civil duty if doing so falls short of exercising reasonable care and skill. Finally, Colleges of Physicians and Surgeons can set out guidelines, policies, or standards which create obligations that physicians must meet or risk professional discipline. For example, the College of Physicians and Surgeons of Ontario Policy on Consent to Treatment clearly establishes a duty to obtain consent before treating a patient.

From our comments so far, it will be clear that we favour a law under which a doctor is not able to withhold or withdraw unilaterally on the basis of his or her opinion that treatment is "futile" or not in the "best interests" of the patient or not "standard practice." And while the foundations of the proposed approach have been implied by the allocution of the values that should underpin such regulation, in this section, we will specifically articulate the elements of our proposed model.

\section{A. Statute Not Common Law}

The first point to be made here is that we propose that reform should occur by way of statute. This would avoid the deficiencies outlined above which arise when law is developed through the courts. A comprehensive legislative model is preferable from both rule of law and access to justice perspectives. Courts and tribunals would continue to have a role in resolving disputes about what should be done in the face of conflict in particular cases but they should be asked to apply rather than make the law.

\section{B. Decision-MaKing Power}

At the heart of this proposed model is the location of decision-making power not with the doctors but with the patient and his or her substitute decision-maker. This authority to decide is qualified (as will be seen below) and can be challenged, but it represents a starting point as to who has the authority to make a decision about treatment or non-treatment. Such an approach gives effect to the values of life and autonomy - decisions about medical treatment begin with the patient, particularly where the proposed decision is to stop treatment

\footnotetext{
107 Criminal Code, RSC 1985, c C-46, s 215(1)(c).

108 Ibid, s 215.

$109 \quad B(R) v$ Children's Aid Society of Metropolitan Toronto, [1995] 1 SCR 315 at para 227; $R v$ Tutton, [1989] 1 SCR 1392.

$110 \quad$ Crits v Sylvester, [1956] SCR 991; Cleveland v Hamilton Health Services Corp (Henderson General Division) et al, 2011 ONCA 244, 277 OAC 178 at para 16.
} 
leading to his or her death. This model also advances the value of equality, as it imposes a barrier to doctors inappropriately determining a life is not worthwhile based on considerations such as age or disability, or that treatment is not worthwhile or effective based on different cultural beliefs or values.

The proposed model also establishes a legal process that promotes the values of procedural fairness and access to justice. By locating the decision-making power with the patient and substitute decision-maker, a doctor and the health system need to engage with them in making decisions, and a doctor is prevented from unilaterally deciding to stop or not start treatment. Entrenching this process in the law requires the provision of information, discussion with a patient about possible treatment options, and transparent decision-making (hence, procedural fairness). It places the burden of challenging a decision about the provision of treatment on those who can best carry it, namely the doctors and the health system (hence, access to justice). It embeds in the decision-making process appropriate recognition and a role for non-clinical values, and limits the role of medicine and doctors accordingly (hence protecting and promoting autonomy, procedural fairness, equality, access to justice, and humility).

\section{Provide Requested Treatment That CAN Work EXCEPT IF LAWful EXCUSE}

As noted above, the patient or substitute decision-makers' authority to decide on treatment is qualified. Specifically, they are limited to deciding about treatment that can work and for which there is no lawful excuse for the doctor not to provide.

\section{TREATMENT THAT WiLl NOT WORK IS NOT A NECESSARY OF LIFE}

The starting point is that doctors should continue to have an obligation to provide patients with the necessaries of life, and patients should be able to request treatment that fits within this category. The term "necessaries of life" is defined in a common sense, factual manner to mean simply treatment that is necessary to sustain life. If treatment is capable of sustaining life, it will be a necessary of life regardless of whether you, I, or the doctor might think it is not worth doing. This avoids sophistry and the lawfulness of a non-treatment decision turning on subjective judgments by doctors (and so advances the value of the rule of law).

This also means that there will be a duty to provide a wide range of treatments but, it should be emphasized, there will not be a duty to provide all treatment. Treatment that "will not work," such as antibiotics for a virus, will not be a necessary of life - it is not capable of sustaining life. This means there will be no duty to provide such treatment and a patient or substitute decision-maker will not be able to lawfully require it to be given.

\section{A LAWFUl ExCUSE Not to TREAT}

But what of the remaining treatments that would constitute a necessary of life? Can a patient or substitute decision-maker always request such treatment and must a doctor always provide it? Absolutely not. There are circumstances in which a doctor should not be obliged 
to provide necessaries of life and these should be clearly articulated. These circumstances would provide the doctor with a "lawful excuse" for not providing treatment. The following circumstances are, we believe on the values discussed earlier, defensible.

\section{i. Receiving Consent to Withhold or}

Withdraw Treatment, or Other Authorization

A doctor should be excused for not providing treatment if, after consultation with the patient or legally authorized substitute decision-maker, consent is given to withhold or withdraw the treatment. This excuse should also extend to consent contained in a valid advance directive, or to authorization in the form of a court order or tribunal decision.

\section{ii. Existence of a Valid Statutory Regime or Government or Institutional Resource Allocation Policy}

Earlier, we noted that imposing limits on when treatment can be provided can be consistent with the value of distributive justice. Rationing of health care is inevitable and ethically appropriate. However, we have argued it must be done overtly, not covertly, and it needs to happen through a process that reflects such values as equality and procedural fairness. Rationing may need to occur both at a governmental level through enactment of legislation or development of departmental policies. It may also occur at the institutional level through hospitals developing policies that are specifically tailored to their own circumstances. This will no doubt be challenging. Broad and meaningful consultation is necessary, as is ensuring that the composition of any drafting team is representative of stakeholders, particularly those who are likely to be adversely affected by such policies. Furthermore, Gender-Based Analysis, Disability and Inclusion-Based Policy Analysis, and Culture-Based Analysis must be performed. ${ }^{111}$ Yet such an exercise is critical to develop a reasoned, coherent, ethical, and just response to this vexed issue.

Regardless of the mechanism used, the statutes and policies need to be developed in a manner and with the result that they are consistent with the values identified above. Doctors should be excused for not providing treatment pursuant to such legislation or policies.

\section{iii. Physical Impossibility}

There may be some situations in which treatment is a physical impossibility. For example, there may be no dialysis machine or oncology services in the town in which the patient lives or can travel to. A doctor should not be liable for not providing the necessaries of life where it is not physically possible to do so. It is likely that such conduct would not be unlawful in any event, even without an excuse, as civil or criminal liability is, as a rule, not imposed for failing to do something which is impossible. Nevertheless, for the sake of clarity and completeness, this should be specifically included in the legislative scheme as providing a lawful excuse for non-treatment. 
iv. Transfer of the Patient to a Doctor

Who Will Provide the Desired Treatment

The value of enabling a doctor to act in accordance with his or her conscience was recognized earlier. A doctor should not be required to provide treatment to a patient if treatment is contrary to his or her conscience, as long as it is possible to transfer the patient to a doctor willing and able to provide that treatment. However, if transfer is not possible, treatment should continue until there is some other lawful excuse not to treat.

\section{CONCLUSION AND A ForWARD-LOOKING CHALlenge}

We have proposed an alternative model for withholding and withdrawing potentially lifesustaining treatment based on the values that we consider are and should be embedded in Canadian law and society: life, autonomy, equality, rule of law, distributive justice, procedural fairness, access to justice, conscience, and humility. We consider that this model represents a principled basis for regulating this difficult area of medical practice and takes into account the various needs and interests of patients, families, health care professionals, and the wider community.

We anticipate that some, perhaps many, will not endorse the suggested approach. Nevertheless, we advocate this model to further the important values that should underpin a legal framework when making decisions about life and death; values we would argue, largely reflect, represent, and promote the values of the Canadian legal system and wider society. We also predict that the cultural shift this model requires is perhaps not as great as may be imagined at first glance, particularly for doctors who currently engage patients and families in a genuine, meaningful, and respectful way in discussions about treatment at the end of life. Our hope is that the adoption of this model will improve outcomes for all, particularly better care for those who are dying and their families.

We conclude with a forward-looking challenge for those readers who are not from Canada. To date we have undertaken this exercise of developing a proposed model for regulating these decisions in a principled way in Australia and New Zealand, ${ }^{112}$ and now in Canada in this article. These are important issues and the inconsistency across countries outlined earlier raises questions about whether the values of those jurisdictions are sufficiently different to warrant that level of legal variation. This points to a need for a principled review in those countries discussed, and indeed in others as well. So we would ask you to:

- Consider whether the values articulated in this article reflect how decisions about withholding and withdrawing potentially life-sustaining treatment should be regulated in your specific legal system.

- $\quad$ Review the legal landscape that applies to such decisions. 
- Hold the law up to those values and consider whether the current approach is justifiable.

- Then, if it is not justifiable, work to reform the law as needed.

- Share your results in the academic literature so that we can all continue to learn from the experiences of one another. 
